\title{
Biomarkers to Predict the Renal Response to Cardiac Resynchronization Therapy During a Three- Month Follow-Up: Prospective Clinical Trial
}

\section{Agnieszka Gala-Bladzinska ( $\sim$ agala.edu@gmail.com )}

Medical College of Rzeszow University https://orcid.org/0000-0001-6617-0852

Tomasz Kubrak

Medical College of Rzeszów University

Joanna Czech

Medical College of Rzeszów University

David Aebisher

Medical College of Rzeszów University

Krzysztof Gargasz

Medical College of Rzeszów University

Mazur Danuta

Department of Cardiology, St Queen Jadwiga Clinical District Hospital Nt2 in Rzeszów

Andrzej Przybylski

Medical College of Rzeszów University

\section{Research}

Keywords: chronic cardio-renal syndrome biomarkers, renal function biomarkers, biomarkers to predict cardiac resynchronization therapy response

Posted Date: August 31st, 2020

DOI: https://doi.org/10.21203/rs.3.rs-61609/v1

License: (c) (1) This work is licensed under a Creative Commons Attribution 4.0 International License. Read Full License 


\section{Abstract}

\section{Background}

Chronic cardiorenal syndrome type 2 (CRS-T2) has a complex pathophysiology. The objective of this study was to assess renal function using biomarkers associated with nephron injury sites in patients with CRS-T2 following cardiac resynchronization therapy (CRT).

\section{Methods}

The research included patients with heart failure in NYHA classes II-IV, in whom CRT devices had been implanted. After 3 months of follow-up, the research group was divided into CRT responders and CRT non-responders. Prior to CRT and after 3 months, renal function was assessed using biomarkers measured in urine and blood samples.

\section{Results}

CRT was implanted in 56 patients (aged $66 \pm 10$ years) with CRS-T2 in the course of coronary artery disease $(n=38 ; 67.9 \%)$ or dilated cardiomyopathy $(n=18)$. Estimated glomerular filtration rate (eGFR CKDEPI) was $68.55 \pm 20.34 \mathrm{~mL} / \mathrm{min} / 1.73 \mathrm{~m}^{2}$. After three months follow-up CRT responder group were assessed showing a significant decrease in serum prostaglandin D2 synthase (sPGD2S) and albuminuria (UACR) concentrations. Urine samples of the CRT non-responder group showed significant $(p<0.05)$ increases in lipocalin associated with neutrophil gelatinase (UNGAL) concentrations, and a decrease in cystatin $\mathrm{C}$ (uCysC) concentration. There were no significant changes in the concentration of serum creatinine (sCr), CysC and eGFR $\mathrm{CKD}_{\text {-EPI }}$ between the CRT responders and CRT non - responders groups.

\section{Conclusions}

The sCr and eGFR $\mathrm{CKD}_{\text {-EPI }}$ assessment are useless in evaluation of renal function three months after CRT implantation. Biomarkers that account for the pathophysiology of nephron injury in CRS-T2 and change significantly after CRT are: SPGD2S, UACR, uCysC, and UNGAL.

\section{Trial registration}

This study is registered with ClinicalTrials.gov, Identifier: NCT04516525. Registered 15 August 2020 Retrospectively registered, $h$ ttps://clinicaltrials.gov/ct2/show/NCT04516525.

\section{Introduction}

Chronic cardiorenal syndrome (CRS-T2) has a complex pathophysiology and an understanding the disease underlies effective causal treatment [1]. Resynchronization therapy (CRT) is a method of treatment in some patients with severe and chronic heart failure (CHF) [2]. Patients with kidney damage are poorly represented in CRT clinical studies due to a lack of guidelines for this group although this 
group of patients have a high-risk of cardiovascular diseases [3]. The available literature describes the relationship between the use of CRT and improvement of renal function $[4,5]$. In contrast, deterioration of renal function observed using serum creatinine and estimated on the basis of glomerular filtration rate (eGFR) are an independent factor worsening long-term prognosis in patients undergoing CRT $[4,6]$. While, due to their limitations, both creatinine and eGFR are not accurate biomarkers for assessing renal function [7]. Analysis biomarkers of site-specific damage to nephron in the injured kidneys of patients treated with CRT due to heart failure, allows for a more accurate assessment of the pathomechanisms underlying CRS-T2. In our study, we evaluated kidney function in patients with CRS-T2 using classic biomarkers such as serum creatinine $(\mathrm{sCr})$ and the estimated glomerular filtration rate (eGFR $\left.\mathrm{CKD}_{\mathrm{EPI}}\right)$ and by using other protein biomarkers that can indicate nephron injury sites with greater precision [8]. The following low molecular weight proteins, freely filtering through the glomeruli and mostly reabsorbed in the proximal tubule of the nephron, were considered indicators of glomerular renal assessment: cystatin $\mathrm{C}$ in urine (uCysC) and serum (sCysC) and lipocalin-type serum prostaglandin D2-synthase (sPGD2S) [9, 10]. We chose urinary lipocalin associated with neutrophil gelatinase (UNGAL) secreted mainly from the distal nephron tubules in response to a nephrotoxic agent or ischemia as biomarker in the assessment of renal tubules $[11,12]$.

The objective of this study was to assess renal function using urine and blood biomarkers pathophysiological associated with nephron injury sites in patients with CRS-T2 treated with CRT and 3 months after implantation.

\section{Materials And Methods}

Between September 2016 and December 2017, 56 patients with heart failure were initially included in the study, and all qualified for CRT by a cardiologist in accordance with applicable criteria of the European Society of Cardiology [13]. The other inclusion criteria for the study are: written consent to participate in the study, patient reporting within 3 months ( \pm 1 week) after implantation for outpatient cardiological and nephrological monitoring, and the possibility of urine and blood testing at any stage of the study. All patients were given a physical examination before CRT implantation, and again 3 months after the procedure. Patient recruitment and CRT implantation were performed during hospitalization at our Cardiology Clinic. The first morning urine and blood samples were collected prior to cardiac resynchronization therapy. Some of the basic laboratory testing was performed at our Clinical Laboratory Diagnostics Department. The urine and serum samples was secured, was stored at $-80^{\circ} \mathrm{C}$ for future use in determining biomarkers.

Table 1 presents demographic, clinical data, and selected laboratory results for the study group prior to CRT implantation. 
Table 1

Selected demographic, clinical data and laboratory results for the research group before CRT implantation

\begin{tabular}{|c|c|}
\hline Variable & $\begin{array}{l}\text { CRS-T2 }(n=56) \\
\text { mean } \pm \text { SD (min-max) }\end{array}$ \\
\hline Age [years] & $66.48 \pm 10.02(43-86)$ \\
\hline Gender, female [n (\%)] & $17(30.36)$ \\
\hline Body weight [kg] & $79.13 \pm 16.18(50.6-114)$ \\
\hline $\mathrm{BMI}\left[\mathrm{kg} / \mathrm{m}^{2}\right]$ & $28.67 \pm 5.38(20.07-44.46)$ \\
\hline NYHA & $25(45.6)$ \\
\hline II [n (\%)] & $25(45.6)$ \\
\hline III [n (\%)] & $6(8.8)$ \\
\hline \multicolumn{2}{|l|}{ IV [n (\%)] } \\
\hline Width QRS [ms] & $162.7 \pm 24.3(130-200)$ \\
\hline LVEF [\%] & $25.3 \pm 7.2(5-35)$ \\
\hline eGFR CKD-EPI $\left[\mathrm{mL} / \mathrm{min} / 1.73 \mathrm{~m}^{2}\right]$ & $68.55 \pm 20.34(21-107)$ \\
\hline $\mathrm{sCr}[\mu \mathrm{mol} / \mathrm{L}]$ & $99.0 \pm 27.4(65.4-179.4)$ \\
\hline $\mathrm{AH}[\mathrm{n}(\%)]$ & $10(18.8)$ \\
\hline CAD [n (\%)] & $38(67.9)$ \\
\hline T2DM [n (\%)] & $25(44.64)$ \\
\hline Cause of heart failure [n (\%)] & $38(67.9)$ \\
\hline CAD & $18(32.1)$ \\
\hline \multicolumn{2}{|l|}{ DCM } \\
\hline Intraventricular conduction disorders [n (\%)] & $42(75.0)$ \\
\hline LBBB & $8(14.29)$ \\
\hline $\begin{array}{l}100 \% \text { right ventricular stimulation rate } \\
\text { other (RBBB, LAH and RBBB) }\end{array}$ & $6(10.71)$ \\
\hline $\mathrm{AF}[\mathrm{n}(\%)]$ & $21(37.5)$ \\
\hline $\begin{array}{l}\text { chronic } \\
\text { paroxysmal }\end{array}$ & $15(26.79)$ \\
\hline
\end{tabular}




\section{Variable}

CRS-T2 $(n=56)$

mean $\pm S D(\min -\max )$

Abbreviations:

$\mathrm{AF}$, atrial fibrillation; $\mathrm{BMI}$, body mass index; $\mathrm{CAD}$, coronary artery disease; CRS-T2, cardiorenal syndrome type 2; DCM, dilated cardiomyopathy; eGFR ${ }_{C K D-E P}$, Chronic Kidney Disease Epidemiology Collaboration equation to estimate glomerular filtration rate; $H A$, arterial hypertension; $L A H$, left anterior hemiblock; LBBB, left bundle branch block; LVEF, left ventricular ejection fraction; NYHA, New York Heart Association classification [14]; QRS, QRS complex; sCR, serum creatynine; RBBB, right bundle branch block; T2DM, diabetes mellitus type 2

In order to assess the impact of CRT on renal function, cardiological and nephrological outpatient follow-up examinations were performed in all patients 3 months after implantation. The results of 33 $(61.11 \%)$ patients with heart failure in the New York Heart Association (NYHA) classes NYHA II-IV [14] including those with ischemic heart disease $(n=20 ; 60.6 \%)$ and patients with dilated cardiomyopathy $(n=13 ; 39.4 \%)$ met the inclusion criteria and were finally selected for analysis. To assess cardiac function, both before implantation and 3 months after implantation the severity of NYHA heart failure symptoms was assessed, the N-terminal fragment of (type B) natriuretic peptide (NT-proBNP) was determined, electrocardiography and transthoracic echocardiogram was performed. The cardiologist, based on current recommendations, assessed the response to CRT and assigned patients to CRT responders or CRT non-responders [13].

To assess renal function, both before and 3 months after CRT, the following were examined: blood count, kalemia, natremia, sCr, eGFR $\mathrm{CKD}_{\text {-EPI}}$, urinary albumin in the first morning sample (uAlb), urinary creatinine in the first morning sample ( $\mathrm{uCr}$ ), and lipocalin associated with uNGAL. The mentioned laboratory tests were performed in the Clinical Laboratory Diagnostics Department immediately after collecting the urine and blood. Urinary NGAL concentrations were determined with the ARCHITECT ${ }^{\circledR}$ Analyzer (Abbott Park, USA) using chemiluminescent microparticle immunoassay. In order to eliminate possible errors resulting from dilution of the urine, the following were also calculated: the albumin-to-creatinine ratio (UACR) and the uNGAL-to-uCr ratio in single samples of urine (UNCR).

The frozen serum and urine samples were tested for: cystatin $\mathrm{C}$ in the urine (uCysC) and in the serum (sCysC), and serum prostaglandin D2-synthase (PTGDS). Tests for proteins determined by the ELISA method were carried out in the laboratory of the Natural and Medical Center for Innovative Research, Institute of Medical Sciences, at the University of Rzeszów.

Human Cystatin $\mathrm{C}$ assay was performed using a commercially available enzyme-linked immunosorbent assay (ELISA) test kit (BioVendor Research and Diagnostic Products, Brno, Czech Republic) and was expressed in nanograms per milliliter ( $\mathrm{ng} / \mathrm{mL}$ ). The Human Cystatin C ELISA is a sandwich enzyme immunoassay for the quantitative measurement of human cystatin $\mathrm{C}$. The kit measures cystatin $\mathrm{C}$ in serum, plasma, urine and cerebrospinal fluid. The Human Cystatin C kit was used for cystatin C quantification in serum samples [15].

PGD2S (Prostaglandin D2 Synthase) assay was determined using a commercially available enzymelinked immunosorbent assay (ELISA) test kit (Cloud-Clone Corp., Katy, Texas, USA) and was expressed in nanograms per milliliter $(\mathrm{ng} / \mathrm{mL}$ ). The kit is a sandwich enzyme immunoassay for in vitro quantitative measurement of PGD2S in human serum, plasma, cerebrospinal fluid and other biological fluids. The PGD2S ELISA kit was used for PGD2S quantification in serum samples [16]. 
All procedures related to protein determination by ELISA were carried out according to the manufacturer's instructions. Reading of the ELISA plates was done with the Spark Reader Tecan Company (Männedorf, Switzerland). The readings were directly made at $450 \mathrm{~nm}$ with reference wavelength $630 \mathrm{~nm}$ by a microtiter plate reader and compared with a standard curve.

Magellan ${ }^{\text {TM }}$ software, used to analyze all the results obtained which allowed for full control of the instrument and data processes and ensuring availability of all necessary information. All samples were measured in duplicate.

All patients included in the study gave their written consent to participate in the research. The study was conducted in accordance with the Declaration of Helsinki and was approved by the Bioethics Committee of the University of Rzeszów (No. 5/04/2016).

\section{Statistical Analysis}

The distribution of continuous data was checked using the Shapiro-Wilks test for normality. Because the data did not meet the assumptions, further comparisons of the changes in individual biochemical parameters before and after 3 months post CRT were made (using the Wilcoxon matched-pairs signedranks test). In order to compare biomarkers in relation to positions on the NYHA scale, the Kruskal-Wallis and ANOVA tests were used. The Statistica 12.5 PL package (Statsoft, Tulsa, USA) was used for analyses. $P$ values $<0.05$ were considered to be statistically significant.

\section{Results}

Table 2. shows the concentration values of urine biomarkers tested before and 3 months after CRT, taking into account laboratory standards and the statistical significance $(p)$ of the changes observed. 
Table 2

Values of concentrations of tested biomarkers in urine before and 3 months after CRT and statistical significance $(p)$ of observed changes in the whole group of patients.

\begin{tabular}{|c|c|c|c|}
\hline Urine biomarker & $\begin{array}{l}\text { Biomarker value } \\
\text { before CRT } \\
\text { mean } \pm \text { SD } \\
\text { median }\end{array}$ & $\begin{array}{l}\text { Biomarker value } \\
3 \text { months after CRT } \\
\text { mean } \pm \text { SD } \\
\text { median }\end{array}$ & $p$ \\
\hline \multirow[t]{2}{*}{ uCysC (ng / mL) } & $1368.9 \pm 1499.0$ & $1083.7 \pm 1478.9$ & 0.151 \\
\hline & 1068.5 & 816.8 & \\
\hline \multirow[t]{2}{*}{ uCysC / uCr (mg / g) } & $1.4 \pm 2.2$ & $1.5 \pm 3.5$ & 0.1 \\
\hline & 0.98 & 0.78 & \\
\hline \multirow[t]{2}{*}{ uAlb (mg / dL) } & $112.9 \pm 169.1$ & $58.9 \pm 130.5$ & $0.024^{*}$ \\
\hline & 10.19 & 5.96 & \\
\hline \multirow[t]{2}{*}{ uACR (ng / mL) } & $132.5 \pm 247.5$ & $51.1 \pm 98.6$ & $0.041 *$ \\
\hline & 9.6 & 5.8 & \\
\hline \multirow[t]{2}{*}{ uNGAL $(\mu \mathrm{g} / \mathrm{L})$} & $28.8 \pm 48.2$ & $43.5 \pm 77.6$ & $0.028 *$ \\
\hline & 13.0 & 19.8 & \\
\hline \multirow[t]{2}{*}{ uNCR $(\mu \mathrm{g} / \mathrm{g})$} & $34.3 \pm 75.5$ & $67.6 \pm 136.6$ & $0.024^{*}$ \\
\hline & 13.7 & 15.2 & \\
\hline
\end{tabular}

Table 3. presents the values of the serum indicators tested before and 3 months after CRT, taking into account the statistical significance of the observed changes. 
Table 3

Values of concentrations of tested biomarkers in serum before and 3 months after CRT, and statistical significance $(p)$ of the changes observed in the whole group of patients.

\begin{tabular}{|c|c|c|c|}
\hline Serum biomarker & $\begin{array}{l}\text { Biomarker value before } \\
\text { CRT } \\
\text { mean } \pm \text { SD } \\
\text { median }\end{array}$ & $\begin{array}{l}\text { Biomarker value } \\
3 \text { months after } \\
\text { CRT } \\
\text { mean } \pm \text { SD } \\
\text { median }\end{array}$ & $p$ \\
\hline sCysC (ng / mL) & $\begin{array}{l}1711.0 \pm 533.4 \\
1617.9\end{array}$ & $\begin{array}{l}1787.6 \pm 573.2 \\
1689.4\end{array}$ & 0.228 \\
\hline sPGD2S (ng / mL) & $\begin{array}{l}247.5 \pm 41.9 \\
249.25\end{array}$ & $\begin{array}{l}215.7 \pm 63.0 \\
225.87\end{array}$ & $0.002^{*}$ \\
\hline $\mathrm{sCr}(\mathrm{mg} / \mathrm{dL})$ & $\begin{array}{l}1.12 \pm 0.31 \\
1.02\end{array}$ & $\begin{array}{l}1.13 \pm 0.45 \\
0.96\end{array}$ & 0.650 \\
\hline $\mathrm{eGFR}_{\mathrm{CKD}-\mathrm{EPI}}\left(\mathrm{mL} / \mathrm{min} / 1.73 \mathrm{~m}^{2}\right)$ & $\begin{array}{l}68.55 \pm 20.34 \\
73.0\end{array}$ & $\begin{array}{l}70.52 \pm 22.83 \\
72.0\end{array}$ & 0.433 \\
\hline $\mathrm{Na}(\mathrm{mmol} / \mathrm{L})$ & $\begin{array}{l}136.21 \pm 3.13 \\
136.0\end{array}$ & $\begin{array}{l}136.48 \pm 4.04 \\
137.0\end{array}$ & 0.290 \\
\hline $\mathrm{K}(\mathrm{mmol} / \mathrm{L})$ & $\begin{array}{l}4.4 \pm 0.5 \\
4.4\end{array}$ & $\begin{array}{l}5.64 \pm 6.9 \\
4.5\end{array}$ & 0.247 \\
\hline RBC (millions K per / $\mu \mathrm{L}$ ) & $\begin{array}{l}4.5 \pm 0.6 \\
4.39\end{array}$ & $\begin{array}{l}4.7 \pm 0.8 \\
4.55\end{array}$ & 0.053 \\
\hline $\mathrm{Hb}(\mathrm{g} / \mathrm{dL})$ & $\begin{array}{l}13.4 \pm 1.5 \\
13.5\end{array}$ & $\begin{array}{l}13.9 \pm 1.4 \\
14.0\end{array}$ & $0.003^{*}$ \\
\hline
\end{tabular}

Abbreviations: eGFR ${ }_{\mathrm{CKD}-\mathrm{EPI}}$, Chronic Kidney Disease Epidemiology Collaboration equation to estimate glomerular filtration rate; $\mathrm{Hb}$, hemoglobin; $\mathrm{HCT}$, hematocrit; $\mathrm{K}$, potassemia; $\mathrm{Na}$, natremia; $\mathrm{RBC}$, red blood cells; sCr, serum creatinine; SCysC, serum cystatin C; SPGD2S, serum prostaglandin D2 synthase; \# - laboratory standards in force at the hospital lab; $p$ - $\mathrm{p}$-value; * - statistical significance.

Next, the correlations between the SPGD2S and selected indicators of renal function before CRT and 3 months after CRT were analyzed. Among others, the presence of a positive correlation between the sPGD2S concentration and the sCr, and a negative correlation between the sPGD2S and the eGFR $_{\text {CKD-EPI }}$ both before and 3 months after CRT were demonstrated. The relationships observed are presented in Table 4. 


\begin{tabular}{|c|c|c|c|}
\hline Serum biomarker & $\begin{array}{l}\text { Biomarker value before } \\
\text { CRT } \\
\text { mean } \pm \text { SD } \\
\text { median }\end{array}$ & $\begin{array}{l}\text { Biomarker value } \\
3 \text { months after } \\
\text { CRT } \\
\text { mean } \pm \text { SD } \\
\text { median }\end{array}$ & $p$ \\
\hline HCT (\%) & $\begin{array}{l}40.35 \pm 4.2 \\
39.3\end{array}$ & $\begin{array}{l}41.9 \pm 3.8 \\
42.4\end{array}$ & $0.004^{*}$ \\
\hline \multicolumn{4}{|c|}{$\begin{array}{l}\text { Abbreviations: eGFR } \mathrm{CKD}_{\mathrm{EP}} \text {, Chronic Kidney Disease Epidemiology Collaboration equation to estimate } \\
\text { glomerular filtration rate; } \mathrm{Hb} \text {, hemoglobin; } \mathrm{HCT} \text {, hematocrit; } \mathrm{K} \text {, potassemia; } \mathrm{Na} \text {, natremia; } \mathrm{RBC} \text {, red } \\
\text { blood cells; sCr, serum creatinine; sCysC, serum cystatin C; sPGD2S, serum prostaglandin D2 } \\
\text { synthase; \# - laboratory standards in force at the hospital lab; } p \text { - } p \text {-value; * - statistical significance. }\end{array}$} \\
\hline \multicolumn{4}{|c|}{$\begin{array}{l}\text { Next, the correlations between the SPGD2S and selected indicators of renal function before CRT and } 3 \\
\text { months after CRT were analyzed. Among others, the presence of a positive correlation between the } \\
\text { SPGD2S concentration and the SCr, and a negative correlation between the SPGD2S and the } \\
\text { eGFR } \\
\text { presD-EPI both before and } 3 \text { months after CRT were demonstrated. The relationships observed are } \\
\text { presented Table } 4 \text {. }\end{array}$} \\
\hline
\end{tabular}


Table 4

Analysis of the correlation between SPGD2S concentration and selected biomarkers before and 3 months after CRT.

\begin{tabular}{|lll|}
\hline Parameter & \multicolumn{2}{l|}{ Spearman's rank correlation coefficient; $\boldsymbol{p}<\mathbf{0 . 0 5}$} \\
\cline { 2 - 3 } & Before implantation & 3 months after implantation \\
\hline $\mathrm{sCr}(\mathrm{mg} / \mathrm{dL})$ & 0.54 & 0.52 \\
\hline $\mathrm{uAlb}(\mathrm{mg} / \mathrm{dL})$ & 0.37 & - \\
\hline $\mathrm{uACR}(\mathrm{ng} / \mathrm{mL})$ & 0.46 & - \\
\hline $\mathrm{uNGAL}(\mu \mathrm{g} / \mathrm{L})$ & 0.36 & - \\
\hline eGFR & -0.39 & -0.44 \\
\hline $\mathrm{Na}\left(\mathrm{mmol} / \mathrm{EPI} / \mathrm{m} / \mathrm{min} / 1.73 \mathrm{~m}^{2}\right)$ & -0.47 & - \\
\hline
\end{tabular}

Abbreviations: eGFR ${ }_{\text {CKD-EPI, }}$ Chronic Kidney Disease Epidemiology Collaboration equation to estimate glomerular filtration rate; $\mathrm{Na}$, natremia; $p$ - $\mathrm{p}$-value; $\mathrm{sCr}$, serum creatinine; uACR, urinary albumin-tocreatinin ratio; uAlb, urinary albumin; uNGAL, urinary lipocalin associated with neutrophil gelatinase

However, there was no correlation between SPGD2S and the left ventricular ejection fraction in the echocardiogram before cardiac resynchronization therapy (Spearman's rank correlation test; $p>0.05$ ), nor were comorbidities such as atrial fibrillation, hypertension, coronary heart disease, T2DM, heart failure etiology and conduction type disorders observed in the ECG (Mann-Whitney U test; $p>0.05$ ). There was also no correlation between the SPGD2S and NYHA heart rate assessment prior to CRT (Cruscal Wallis test; $p=0.6$ ).

Then, the cardiologist, based on current recommendations, assessed the response to CRT and assigned patients to CRT responders or CRT non-responders [13]. The group of 21 (63.63\%) patients were included to the CRT responders after 3 months of follow-up.

In the group of CRT responders, we observed a statistically significant change in the selected blood count parameters like: RBC, Hb, HCT. The observed correlations are presented in Fig. 1.

Figure 1. Graph showing statistically significant changes in RBC (a), Hb (b), HCT (c) in patients before and 3 months after CRT in the CRT responders group $(n=21)$.

Also, in CRT responders group we observed significant decreases in both UACR and SPGD2S concentrations. The observed correlations are presented in Fig. 2.

Figure 2. Graph showing statistically significant changes in UACR (a) and SPGD2S (b) before and 3 months after CRT in the CRT responders group $(n=21)$.

In addition, a statistically significant increase in UNGAL concentration and a significant decrease in uCysC concentration in CRT non-responders group 3 months after CRT was observed. The responders did not show any statistically significant changes in either urine biomarkers. The significant relationships observed in the CRT non - responders group are shown in Fig. 3. 
Figure 3. Graph showing statistically significant changes in UNGAL (a) and uCysC (b) before and 3 months after CRT in the CRT non - responders group $(n=12)$.

At the same time, in both responders and nonresponders, no statistically significant changes in other biomarkers were observed.

\section{Discussion}

It is well known that CRS is characterized by complex interactions between the cardiac and renal mediated by hemodynamic, neurohormonal and endothelial dysfunction. The kidneys play a key role in maintaining hemodynamic balance, which is often disturbed in patients with HF $[17,18]$. In addition, kidney disease is an independent risk factor for sudden cardiac death due to the higher frequency of cardiac arrhythmias in patients with CKD [19].

Literature data indicate that CHF and CKD coexist in 45-63\% [20,21]. In our work, we observed that patients suffered from primary heart injury either due to coronary artery disease or dilated cardiomyopathy. The pathophysiology of CRS-T2 includes renal hyperemia with hypoperfusion resulting from an increase in right atrial pressure and a low cardiac output [22]. In clinical practice, when treating a patient with CRS-T2, we should effectively treat all the pathophysiological causes of cardiorenal syndrome. One of the treatment methods for patients with symptomatic systolic heart failure with concomitant intraventricular conduction block, despite optimal pharmacological therapy is CRT. Resynchronization is one of the most promising therapies with proven benefits for HF patients, such as: improvement of left ventricular function, reduction of CHF symptoms, and reduced mortality from any cause $[23,24]$. CRT involves two-chamber stimulation to allow coordinated contraction or greater synchronization between both ventricles. This intervention should improve myocardial function and may be particularly attractive in selected individuals with CKD [25]. It is known, however, that patients who do not respond to such CRT treatment (non - responders) have a much higher risk of re-hospitalization and mortality [26]. Therefore, it is important to identify patients who do not respond to CRT therapy. Meanwhile, few randomized controlled studies have been undertaken to assess the effect of resynchronization in patients with kidney damage [27, 28].

In clinical settings, evaluation of $\mathrm{sCr}$ and the eGFR as potential biomarkers of renal function are inaccurate. Many factors independent of renal function affect $\mathrm{sCr}$, including: age, gender, muscle mass, metabolism, drugs, and hydration rate [29]. For these reasons, either the absolute or the relative increases in baseline $\mathrm{sCr}$ are indicative of a worsening of renal function. In our study, no differences were observed in the concentrations of $\mathrm{sCr}$ and $\mathrm{eGFR}_{\mathrm{CKD} \text {-EPI }}$ in in the entire group of patients both before and 3 months after CRT. Moreover, in our study we did not observe differences in the concentrations of $\mathrm{sCr}$ and eGFR $_{\text {CKD-EPI }}$ both in the CRT responders group and in the CRT non-responders group. This observation confirms the limited utility of SCR and eGFR $\mathrm{R}_{\mathrm{CKD}-E P I}$ in the assessment of renal function in patients with CRS-T2 receiving resynchronization. Our observations are also confirmed by the other researchers $[27,28$, $30,31]$. 
Therefore, considering the limitations of sCr and eGFR as biomarkers of renal function in people after CRT, we have explored new alternative biomarkers.

NGAL is one of the low molecular weight proteins $(25 \mathrm{kDa})$ whose role in the assessment of renal function after cardiac resynchronization therapy was investigated in a population of patients with CRST2. It is a low molecular weight protein associated with human neutrophil gelatinase, whose urine assay is considered a useful indicator of the course of acute kidney injury in the prerenal mechanism [11]. The appearance of this protein in the urine of patients in the early stages of CKD, gives useful diagnostic information as to the sites and degree of injury to the renal interstitium [12]. In patients with CHF, increased UNGAL may be a marker of tubulo-interstitial injury and is associated with an increased risk of worsening renal function, increased hospitalization and overall mortality [33]. In addition, it was observed in a study by Damman et al., that in a group of patients with CHF, an increase in the NGAL-to-creatinine ratio in the urine was an indication of renal tubular injury [34]. In our study, it was observed that in the group of non - responder patients 3 months after CRT treatment, the concentration of NGAL in urine was significantly higher compared with concentrations before CRT. Hence, the increase in uNGAL should be considered as a biomarker of nonresponse to resynchronization 3 months after CRT therapy. The role of NGAL as an indicator of inflammation in the body should also be noted [32]. Studies by other scientists confirm the important role of NGAL in the pathogenesis of atherosclerosis and its associated inflammation $[35,36]$. In contrast, slight inflammation is a component of the pathomechanism HF [37, 38]. Therefore, the increased concentration of NGAL in urine that we observed in our study in the group of CRT non - responders may be a sign of more intense systemic inflammation and tubulitis than that observed in the CRT responders group.

Another biomarker whose significant change we observed in the non - responders in our study was urine cystatin C. CysC is a low molecular weight (13-kDa) polypeptide. It is an endogenous inhibitor of cysteine proteinases, produced by all nuclear cells, that is released into the blood. Under normal physiological conditions, CysC is freely filtered from the blood into the primary urine through the glomeruli, then reabsorbed and catabolized by proximal tubules cells, and its concentration in blood serum is not dependent on age, gender, race or body weight. CysC plays the role of an early marker for both acute and chronic kidney injury $[39,40]$. In the study by Menon et al., it was observed that in a population of patients with CKD, a higher concentration of serum CysC was associated with an increased risk of renal failure, and overall mortality from cardiovascular causes [41]. However, in the research of Dupont M. et al. [42] in a group of patients with $\mathrm{CHF}$, the concentration of $\mathrm{SCysC}$ was strongly correlated with classic renal function biomarkers like creatinine and eGFR, and remained an independent predictor of serious adverse cardiovascular events. In our study, we did not observe changes in SCysC after CRT both in the whole group and in groups divided according to the response to CRT. However, we did observe a significant decrease in CysC in the urine of CRT non - responders. The relationship we observed was probably due to impaired free $\mathrm{SCysC}$ filtration in the glomerulus during the course of CRS-T2 in those patients whose myocardial function did not improve after CRT. Both CysC and albuminuria represent biomarkers of glomerular filtration barrier and its integrity in CRS. According to current recommendations, uAlb concentrations in the daily urine collection of less than $30 \mathrm{mg} / \mathrm{dL}$, and an urinary albumin-to-creatinin 
ratio (UACR) in the first morning portion of urine of less than $30 \mathrm{mg} / \mathrm{g}$, indicate normal kidney function [43]. Based on 3 large studies conducted in a population of patients with HF, it is known that albuminuria has a strong prognostic value for all-cause mortality, cardiovascular death, and rehospitalization [44-46]. In our study, 3 months after CRT therapy, we observed a decrease in albuminuria in the entire group of CRT responders. This observation was probably the effect of a decrease in glomerular filtration pressure in those patients with an improvement cardiac function in CRT responders group. In nephrological practice, a decrease in albuminuria is an important treatment goal for most nephropathy, due to the proven relationship between albuminuria normalization and long-term improvement in renal function and reduced cardiovascular complications in nephrological patients [47]. Therefore, a significant decrease in uACR three months after CRT, seems to have important clinical significance and may be a useful prognostic tool for cardiologists and nephrologists treating patients with CRS-T2.

Lipocalin-type prostaglandin D2-synthase (PGD2S), also known as $\beta$-Trace protein (BTP), is another biomarker whose usefulness in assessing kidney function in patients 3 months after CRT. SPGD2S is a low molecular weight ( 23 to $29 \mathrm{kDa}$ ) glycoprotein that converts prostaglandin $\mathrm{H} 2$ to prostaglandin $\mathrm{D} 2$. The SPGD2S protein is unique among prostaglandins due to its presence in high concentrations in the mammalian brain. The serum gradient of sPGD2S concentration in the cerebrospinal fluid is 32:1 [40]. Its low molecular weight allows free filtration in the glomeruli, with minimal non-renal excretion and no secretion into the renal tubules. BTP is stable in urine for 24 hours regardless of urine $\mathrm{pH}$ [48]. In recent years, SPGD2S has proved to be a promising new endogenous, non-age, gender or ethnic origin glomerular filtration biomarker as an alternative to CysC. In addition to its role in assessing kidney function, SPGD2S is also a new biomarker for cardiovascular risk [49-51]. It was observed in the study by Manzano-Fernández S. et al. that SPGD2S predicts the risk of death and / or HF hospitalization and is superior to standard measures of renal function in patients treated with diuretics due to decompensated HF [52]. In the available literature, we did not find any studies that evaluated the usefulness of SPGD2S in assessing kidneys in response to CRT. In our study, SPGD2S proved to be a biomarker that correlated with classic renal function assessment biomarkers such as $\mathrm{SCr}$ and eGFR $\mathrm{CKD}_{\text {EPI. }}$. Also SPGD2S, with the highest statistical significance, positively correlated with clinical improvement, assessed on the NYHA scale, in patients 3 months after CRT.

Anemia is one of the more common associated diseases of HF. In the Study of Left Ventricular Dysfunction (SOLVD), anemia occurred in $22 \%$ of patients with HF and contributed to the severity of HF symptoms [53]. The incidence of anemia increases with the worsening of cardiac failure symptoms from $9 \%$ in NYHA class I to $79 \%$ in NYHA class IV [54]. In a retrospective analysis of the SOLVD study results, low absolute hematocrit values in patients with HF were associated with increased mortality and a higher frequency of hospitalization [53]. Hence, in our study, the increased hematocrit observed after cardiac resynchronization therapy in our population would seem to be a good prognostic marker. This conclusion, however, requires confirmation over a longer follow-up period. Anemia pathomechanisms in patients with CHF include overhydration (which is also indirectly demonstrated by a decrease in hematocrit), deterioration of endocrine kidney function (reduced production of renin, increased production of 
erythropoietin), and the presence of subclinical inflammation associated with CHF [55]. In our study, we observed a statistically significant increase in hemoglobin and erythrocyte counts in CRT respondents. The increase in $\mathrm{Hb}$ concentration and the RBC numbers indicate the "silencing" of many pathomechanisms of anemia in patients with improved cardiac performance after CRT. The simultaneous, statistically significant increase in HCT in the CRT responders group may indicate a lower fluid retention in patients with HF after CRT.

Despite some interesting observations and results, in our opinion, the current research work has its limitations. The limitations of the study is that the majority of the biomarkers tested were assessed using methods that could not be used in clinical conditions at the patient's bedside. In the future, it would be reasonable to assess the sensitivity and specificity of the biomarkers SPGD2S, UACR, UCysC, and UNGAL in a larger group of patients after cardiac resynchronization therapy, with a longer follow-up period, and an evaluation of the correlation of results with the frequency of rehospitalization and mortality.

\section{Conclusions}

To our knowledge, this study is one of the few in the available literature assessing kidney function using several biomarkers associated pathophysiologically with the site of nephron injury in patients with CRST2 after cardiac resynchronization therapy. In our work, we have shown that the assessment of renal function in the studied population using classic biomarkers such as serum creatinine or glomerular filtration assessment using eGFR $\mathrm{CKD}_{\mathrm{EPI}}$ does not allow the selection of a group of people who, as a consequence of improved cardiac functio, actually improved their kidney function. Hence, we conclude that in patients with CRS-T2 undergoing resynchronization therapy, in order to select CRT responders, the following proteins should be tested: SPGD2S, UACR, uCysC, UNGAL, HCT, RBC and Hb. It would be advantageous to verify the key results of our study in a larger population of patients.

\section{Abbreviations}

$\mathrm{AF}$ - atrial fibrillation

$\mathrm{AH}$ - arterial hypertension

$\mathrm{BMI}$ - body mass index

CAD - coronary artery disease

CHF - chronic heart failure

CRS-T2 - cardiorenal syndrome type 2

CRT - cardiac resynchronization therapy

DCM - dilated cardiomyopathy 
eGFR $_{\text {CKD-EPI }}$ - Chronic Kidney Disease Epidemiology Collaboration equation to estimate glomerular filtration rate

$\mathrm{LAH}$ - left anterior hemiblock

LBBB - left bundle branch block

LVEF - left ventricular ejection fraction

NT-proBNP - the N-terminal fragment of (type B) natriuretic peptide

NYHA - New York Heart Association classification

QRS - QRS complex

RBBB - right bundle branch block

$\mathrm{sCr}$ - serum creatynine

sCysC - serum cystatin C

sPGD2S - serum prostaglandin D2 synthase

T2DM - diabetes mellitus type 2

UACR - the albumin-to-creatinine ratio in single samples of urine

$\mathrm{uCr}$ - urinary creatinine in the first morning sample

uCysC - cystatin $\mathrm{C}$ in the urine

UNCR - NGAL to creatynine ratio in single samples of urine

UNGAL - urinary lipocalin associated with neutrophil gelatinase

\section{Declarations}

\section{Ethical Approvaland Consent to participate}

All patients included in the study gave their written consent to participate in the research. The study was conducted in accordance with the Declaration of Helsinki and was approved by the Bioethics Committee of the University of Rzeszów (No. 5/04/2016).

\section{Consent for publication}

Not applicable. 
Availability of supporting data

The datasets used and/or analyzed in the current study are available from the corresponding author on reasonable request.

\section{Competing interests}

Not applicable.

\section{Funding}

This research project was financially supported by University of Rzeszów, Poland (Decision No. WM/35.DS/2018).

\section{Authors' contributions}

AGB - designed the study, treated patients, recruited patients for the study, analyzed and interpreted the patient data, was a major contributor in writing the manuscript; TK - drafted the manuscript, performed laboratory tests; JC - drafted the manuscript, performed laboratory tests; DA - drafted the manuscript, analyzed and interpreted the patient data; KG - drafted the manuscript, analyzed and interpreted the patient data; MD - recruited patients for the study, treated patients, analyzed and interpreted the patient data; AP - designed the study, recruited patients for the study, treated patients. All authors read and approved the final manuscript.

\section{Acknowledgements}

Not applicable.

\section{References}

1. Ronco C, Bellasi A, Di Lullo L. Cardiorenal Syndrome: An Overview. Adv Chronic Kidney Dis. 2018 Sep;25(5):382-90. DOI: 10.1053/j.ackd.2018.08.004.

2. Cannizzaro LA, Piccini JP, Patel UD, Hernandez AF. Device therapy in heart failure patients with chronic kidney disease. J Am Coll Cardiol. 2011 Aug;58(9):889-96. DOI:10.1016/j.jacc.2011.05.024.

3. Höke U, Khidir MJH, van der Velde ET, Schalij MJ, Bax JJ, Delgado V, et al. Cardiac resynchronization therapy in chronic kidney disease stage 4 patients. Clin J Am Soc Nephrol. 2015 Oct;10(10):1740-8. DOI:10.2215/CJN.00620115.

4. Chen $\mathrm{HH}$. Beta trace-protein versus cystatin $\mathrm{C}$ : Which is a better surrogate marker of renal function versus prognostic indicator in cardiovascular diseases? Am Coll Cardiol. 2011 Feb;57(7):859-69. DOI:10.1016/j.jacc.2010.09.052.

5. Goldenberg I, Hall WJ, Beck CA, Moss AJ, Barsheshet A, McNitt S, et al. Reduction of the risk of recurring heart failure events with cardiac resynchronization therapy: MADIT-CRT (Multicenter 
Automatic Defibrillator Implantation Trial With Cardiac Resynchronization Therapy). J Am Coll Cardiol. 2011 Aug;58(7):729-37. DOI:10.1016/j.jacc.2011.04.024.

6. Earley A, Miskulin D, Lamb EJ, Levey AS, Uhlig K. Estimating equations for glomerular filtration rate in the era of creatinine standardization: a systematic review. Ann Intern Med. 2012 Jun;156(11):78595. DOI:10.7326/0003-4819-156-6-201203200-00391.

7. Fu S, Zhao S, Ye P, Luo L. Biomarkers in Cardiorenal Syndromes. Biomed Res Int. 2018 Mar;2018:9617363. DOI: 10.1155/2018/9617363.

8. Chapter 1: Definition and classification of CKD. Kidney Int Suppl. (2011). 2013;3(1):19-62. doi:10.1038/kisup.2012.64.

9. Spanaus KS, Kollerits B, Ritz E, Hersberger M, Kronenberg F, von Eckardstein A. Serum creatinine, cystatin $\mathrm{C}$, and beta-trace protein in diagnostic staging and predicting progression of primary nondiabetic chronic kidney disease. Clin Chem. 2010 May;56(5):740-9. DOI: 10.1373/clinchem.2009.138826.

10. Vynckier LI, Flore KMJ, Delanghe SE, Delanghe JR. Urinary $\beta$-trace protein as a new renal tubular marker. Clin Chem. 2009 Jun;55(6):1241-3. DOI:10.1373/clinchem.2008.119727.

11. Devarajan P. Biomarkers for the early detection of acute kidney injury. Curr Opin Pediatr. 2011 Apr;23(2):194-200. DOI:10.1097/MOP.0b013e328343f4dd.

12. Gala-Błądzińska A, Dumnicka P, Kuśnierz-Cabala B, Rybak K, Drożdż R, Żyłka A, et al. Urinary Neutrophil Gelatinase-Associated Lipocalin Is Complementary to Albuminuria in Diagnosis of EarlyStage Diabetic Kidney Disease in Type 2 Diabetes. Biomed Res Int. 2017;2017:4691389. DOI:10.1155/2017/4691389.

13. European Society of Cardiology (ESC); European Heart Rhythm Association (EHRA). Brignole M, Auricchio A, Baron-Esquivias G, Bordachar P, et al. 2013 ESC guidelines on cardiac pacing and cardiac resynchronization therapy: the task force on cardiac pacing and resynchronization therapy of the European Society of Cardiology (ESC). Developed in collaboration with the European Heart Rhythm Association (EHRA). Europace. 2013 Aug;15(8):1070-118. DOI:10.1093/europace/eut206.

14. The Criteria Committee of the New York Heart Association. Nomenclature and Criteria for Diagnosis of Diseases of the Heart and Great Vessels. 9th ed. Boston: Little, Brown \& Co; 1994. pp. 253-6.

15. Delanaye P, Cavalier E, Krzesinski JM. Cystatin C. renal function, and cardiovascular risk. Ann Intern Med. 2008 Feb;148(4):323.

16. Jordan W, Tumani H, Cohrs S, Eggert S, Rodenbeck A, Brunner E, et al. Prostaglandin D synthase (beta-trace) in healthy human sleep. Sleep. 2004 Aug;27(5):867-74.

17. a systematic approach for consensus

Cardio-renal syndromes

Ronco C, Ronco F. Cardio-renal syndromes: a systematic approach for consensus.

18. definition and classification. Heart Fail Rev. 2012 Mar;17(2):151-60.

19. Rangaswami J, Bhalla V, Blair JEA, Chang TI, Costa S, Lentine KL, et al American Heart Association Council on the Kidney in Cardiovascular Disease and Council on Clinical Cardiology. Cardiorenal 
Syndrome: Classification, Pathophysiology, Diagnosis, and Treatment Strategies: A Scientific Statement From the American Heart Association. Circulation. 2019 Apr;139(16):e840-78. DOI:10.1161/CIR.0000000000000664.

20. Di Lullo L, Rivera R, Barbera V, Bellasi A, Cozzolino M, Russo D, et al. Sudden cardiac death and chronic kidney disease: from pathophysiology to treatment strategies. Int J Cardiol. 2016 Aug;217:16-27. DOI:10.1016/j.ijcard.2016.04.170.

21. Heywood JT, Fonarow GC, Costanzo MR, Mathur VS, Wigneswaran JR, Wynne J. High prevalence of renal dysfunction and its impact on outcome in 118,465 patients hospitalized with acute decompensated heart failure: a report from the ADHERE database. J Card Fail. 2007;13(6):422-30.

22. Cruz DN, Bagshaw SM. Heart-kidney interaction: epidemiology of cardiorenal syndromes. Int J Nephrol. 2010;2011:351291.

23. Nohria A, Hasselblad V, Stebbins A, et al. Cardiorenal interactions: insights from the ESCAPE trial. J Am Coll Cardiol. 2008;51(13):1268-74.

24. Cleland JG, Daubert JC, Erdmann E, Freemantle N, Gras D, Kappenberger L, et al. The effect of cardiac resynchronization on morbidity and mortality in heart failure. N Engl J Med. 2005 Apr;352(15):1539-49.

25. Goldenberg I, Kutyifa V, Klein HU, Cannom DS, Brown MW, Dan A, et al. Survival with cardiacresynchronization therapy in mild heart failure. N Engl J Med. 2014 May;370(18):1694-701. DOI:10.1056/NEJMoa1401426.

26. Obeng-Gyimah EK, Deo R. Cardiorenal Resynchronization Therapy: Strengthening the Heart and Kidneys. Clin J Am Soc Nephrol. 2015 Oct;10(10):1705-7. DOI:10.2215/CJN.09120815.

27. Ponikowski P, Voors AA, Anker SD, Bueno H, Cleland JG, Coats AJ, et al. ESC Guidelines for the diagnosis and treatment of acute and chronic heart failure: The Task Force for the diagnosis and treatment of acute and chronic heart failure of the European Society of Cardiology (ESC). Developed with the special contribution of the Heart Failure Association (HFA) of the ESC. European Heart Journal. 2016 Jul 14;37(27):2129-2200. DOI: 10.1093/eurheartj/ehw128.

28. Boerrigter G, Costello-Boerrigter LC, Abraham WT, Sutton MG, Heublein DM, Kruger KM, et al. Cardiac resynchronization therapy improves renal function in human heart failure with reduced glomerular filtration rate. J Card Fail. 2008 Sep;14(7):539-46. DOI: 10.1016/j.cardfail.2008.03.009239.

29. Boerrigter G, Costello-Boerrigter LC, Abraham WT, St John Sutton MG, Heublein DM, Kruger KM, et al. Response to cardiac resynchronization therapy improves renal function: importance of forward and backward failure. J Card Fail. 2009 Feb;15:79-80. DOI: 10.1016/j.cardfail.2008.11.001.

30. Bellomo R. Acute renal failure. Semin Respir Crit Care Med. 2011 Oct;32(5):639-50.

31. Magne J, Dubois M, Champagne J, Dumesnil JG, Pibarot P, Philippon F, et al. Usefulness of NT-pro BNP monitoring to identify echocardiographic responders following cardiac resyn-chronization therapy. Cardiovasc Ultrasound. 2009 Aug;7:39. DOI:10.1186/1476-7120-7-39.

32. Eisen A, Suleiman M, Strasberg B, Sela R, Rosenheck S, Freedberg NA, et al. Renal dysfunction and clinical outcomes of patients undergoing ICD and CRTD implantation: data from the Israeli ICD 
registry. J Cardiovasc Electrophysiol 2014 Sep;25(9):990-7. DOI: 10.1111/jce.12442 242.

33. Moschen AR, Adolph TE, Gerner RR, Wieser V, Tilg H. Lipocalin-2: A Master Mediator of Intestinal and Metabolic Inflammation. Trends Endocrinol Metab. 2017 May;28(5):388-97. DOI: 10.1016/j.tem.2017.01.003.

34. $10.1016 /$ j.cca.2010.10.011

Delanaye P, Rozet E, Krzesinski JM, Cavalier E. Urinary NGAL measurement: biological var-iation and ratio to creatinine. Clin Chim Acta. 2011 Jan 30;412(3-4):390. DOI: 10.1016/j.cca.2010.10.011.

35. Damman K, van Veldhuisen DJ, Navis G, Voors AA, Hillege HL. Urinary neutrophil gelatinase associated lipocalin (NGAL), a marker of tubular damage, is increased in patients with chronic heart failure. Eur J Heart Fail. 2008 Oct;10(10):997-1000. DOI: 10.1016/j.ejheart.2008.07.001.

36. Wu G, Li H, Fang Q, Jiang S, Zhang L, Zhang J, et al. Elevated circulating lipocalin-2 levels independently predict incident cardiovascular events in men in a population-based cohort. Arterioscler Thromb Vasc Biol. 2014 Nov;34(11):2457-64. DOI:10.1161/ATVBAHA.114.303718.

37. Liu KD, Yang W, Go AS, Anderson AH, Feldman HI, Fischer MJ, et al. Urine neutrophil gelatinaseassociated lipocalin and risk of cardiovascular disease and death in CKD: results from the Chronic Renal Insufficiency Cohort (CRIC) Study. Am J Kidney Dis. 2015 Feb;65(2):267-74. DOI:10.1053/j.ajkd.2014.07.025.

38. Gomberg-Maitland M, Shah SJ, Guazzi M. Inflammation in Heart Failure With Preserved Ejection Fraction: Time to Put Out the Fire. JACC Heart Fail. 2016 Apr;4(4):325-8. DOI:10.1016/j.jchf.2015.11.013.

39. Franssen C, Chen S, Unger A, Korkmaz HI, De Keulenaer GW, Tschöpe C, et al. Myocardial Microvascular Inflammatory Endothelial Activation in Heart Failure With Preserved Ejection Fraction. JACC Heart Fail. 2016 Apr;4(4):312-24. DOI: 10.1016/j.jchf.2015.10.007.

40. Tian S, Kusano E, Ohara $T$, Tabei $K$, Itoh $Y$, Kawai $T$, et al. Cystatin $C$ measurement and its practical use in patients with various renal diseases. Clin Nephrol. 1997 Aug;48(2):104-8.

41. Bacci M, Cavallari MR, de Rozier-Alves RM, Alves Bda C, Fonseca FL. The impact of lipocalin-typeprostaglandin-D-synthase as a predictor of kidney disease in patients with type 2 diabetes. Drug Des Devel Ther. 2015 Jun;22:9:3179-82. DOI:10.2147/DDDT.S82100.

42. Menon V, Shlipak MG, Wang X, Coresh J, Greene T, Stevens L, et al. Cystatin C as a risk factor for outcomes in chronic kidney disease. Ann Intern Med. 2007 Jul;147(1):19-27.

43. Dupont M, Wu Y, Hazen SL, Tang WH. Cystatin C Identifies Patients With Stable Chronic Heart Failure at Increased Risk for Adverse Cardiovascular Events. Circ Heart Fail. 2012 Sep 1;5(5):602-9.

44. Levin A, Stevens PE, Bilous RW, et al. Kidney disease: Improving global outcomes (KDIGO) CKD work group. KDIGO 2012 clinical practice guideline for the evaluation and manage-ment of chronic kidney disease. Kidney International Supplements. 2013 Jan;3(1):1-150. https://doi.org/10.1038/kisup.2012.73.

45. Jackson CE, Solomon SD, Gerstein HC, Zetterstrand S, Olofsson B, Michelson EL, et al. Albuminuria in chronic heart failure: prevalence and prognostic importance. Lancet. 2009 Aug;374(9689):543-50. 
DOI:10.1016/S0140-6736(09)61378-7.

46. Masson S, Latini R, Milani V, Moretti L, Rossi MG, Carbonieri E, et al. Prevalence and prognostic value of elevated urinary albumin excretion in patients with chronic heart failure: data from the GISSI-Heart Failure trial. Circ Heart Fail. 2010 Jan;3(1):65-72. DOI:10.1161/CIRCHEARTFAILURE.109.881805.

47. Anand IS, Bishu K, Rector TS, Ishani A, Kuskowski MA, Cohn JN. Proteinuria, chronic kidney disease, and the effect of an angiotensin receptor blocker in addition to an angiotensin-converting enzyme inhibitor in patients with moderate to severe heart failure. Circulation. 2009 Oct;120(16):1577-84. DOI:10.1161/CIRCULATIONAHA.109.853648.

48. Lambers Heerspink HJ, Gansevoort RT. Albuminuria Is an Appropriate Therapeutic Target in Patients with CKD: The Pro View. Clin J Am Soc Nephrol. 2015 Jun;10(6):1079-88.

DOI:10.2215/CJN.11511114.

49. Vynckier LI, Flore KMJ, Delanghe SE, Delanghe JR. Urinary $\beta$-trace protein as a new renal tubular marker. Clin Chem. 2009 Jun;55(6):1241-3. DOI:10.1373/clinchem.2008.119727.

50. 10.1093/ndt/gfy025

Enko D, Meinitzer A, Scharnagl H, Stojakovic T, Kleber ME, Delgado GE, et al. Prospective cohort studies of beta-trace protein and mortality in haemodialysis patients and patients undergoing coronary angiography. Nephrol Dial Transplant. 2018 Nov 1;33(11):1984-91. DOI: 10.1093/ndt/gfy025.

51. Orenes-Piñero E, Manzano-Fernández S, López-Cuenca Á, Marín F, Valdés M, Januzzi JL. $\beta$-Trace protein: from GFR marker to cardiovascular risk predictor. Clin J Am Soc Nephrol. 2013 May;8(5):873-81. DOI:10.2215/CJN.08870812.

52. Foster MC, Levey AS, Inker LA, Shafi T, Fan L, Gudnason V, et al. Non-GFR Determinants of LowMolecular-Weight Serum Protein Filtration Markers in the Elderly: AGES-Kidney and MESA-Kidney. Am J Kidney Dis. 2017 Sep;70(3):406-414. DOI: 10.1053/j.ajkd.2017.03.021.

53. Manzano-Fernández S, Januzzi JL Jr, Boronat-Garcia M, Bonaque-González JC, Truong QA, PastorPérez FJ, et al. $\beta$-trace protein and cystatin $\mathrm{C}$ as predictors of long-term outcomes in patients with acute heart failure. J Am Coll Cardiol. 2011 Feb;15(7):849-58. DOI:10.1016/j.jacc.2010.08.644. 57 ) .

54. de Denus S, Tardif JC, White M, Bourassa MG, Racine N, Levesque S, et al. Temporal variations in hematocrit values in patients with left ventricular dysfunction: Relationship with cause-specific mortality and morbidity and optimal monitoring-further insights from SOLVD. Can J Cardiol. 2008 Jan;24(1):45-8.

55. Das SR, Dries DL, Drazner MH, Yancy CW, Chae CU. Relation of lower hematocrit to progression from asymptomatic left ventricular dysfunction to symptomatic heart failure (from the Studies of Left Ventricular Dysfunction Prevention trial). Am J Cardiol. 2005 Sep;96(6):827-31.

56. Grote Beverborg N, van Veldhuisen DJ, van der Meer P. Anemia in Heart Failure: Still Relevant? JACC Heart Fail. 2018 Mar;6(3):201-208. DOI: 10.1016/j.jchf.2017.08.023.

\section{Figures}




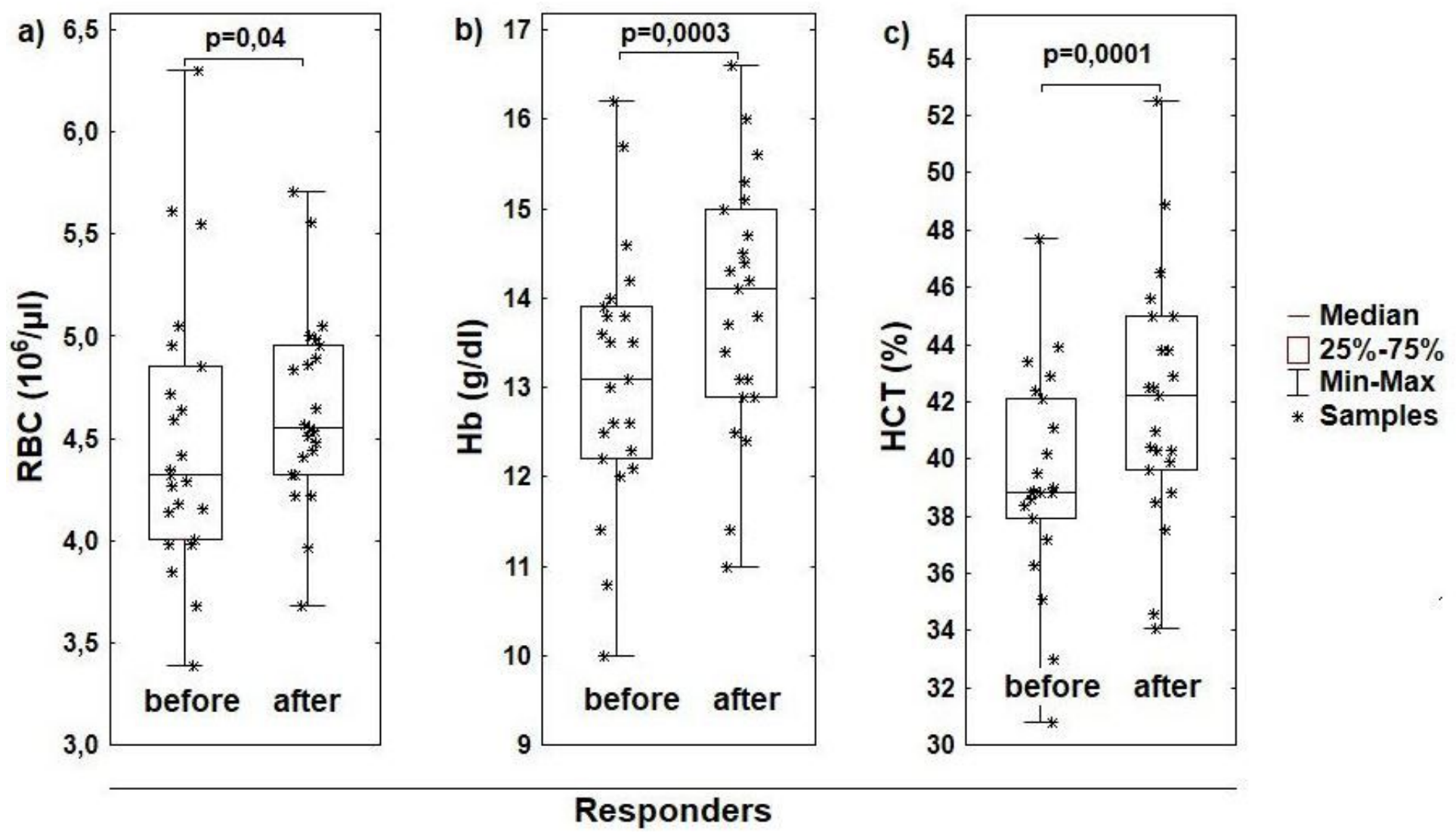

Figure 1

Graph showing statistically significant changes in RBC (a), Hb (b), HCT (c) in patients before and 3 months after CRT in the CRT responders group $(n=21)$. Also, in CRT responders group we observed significant decreases in both UACR and SPGD2S concentrations. The observed correlations are presented in Figure 2. 


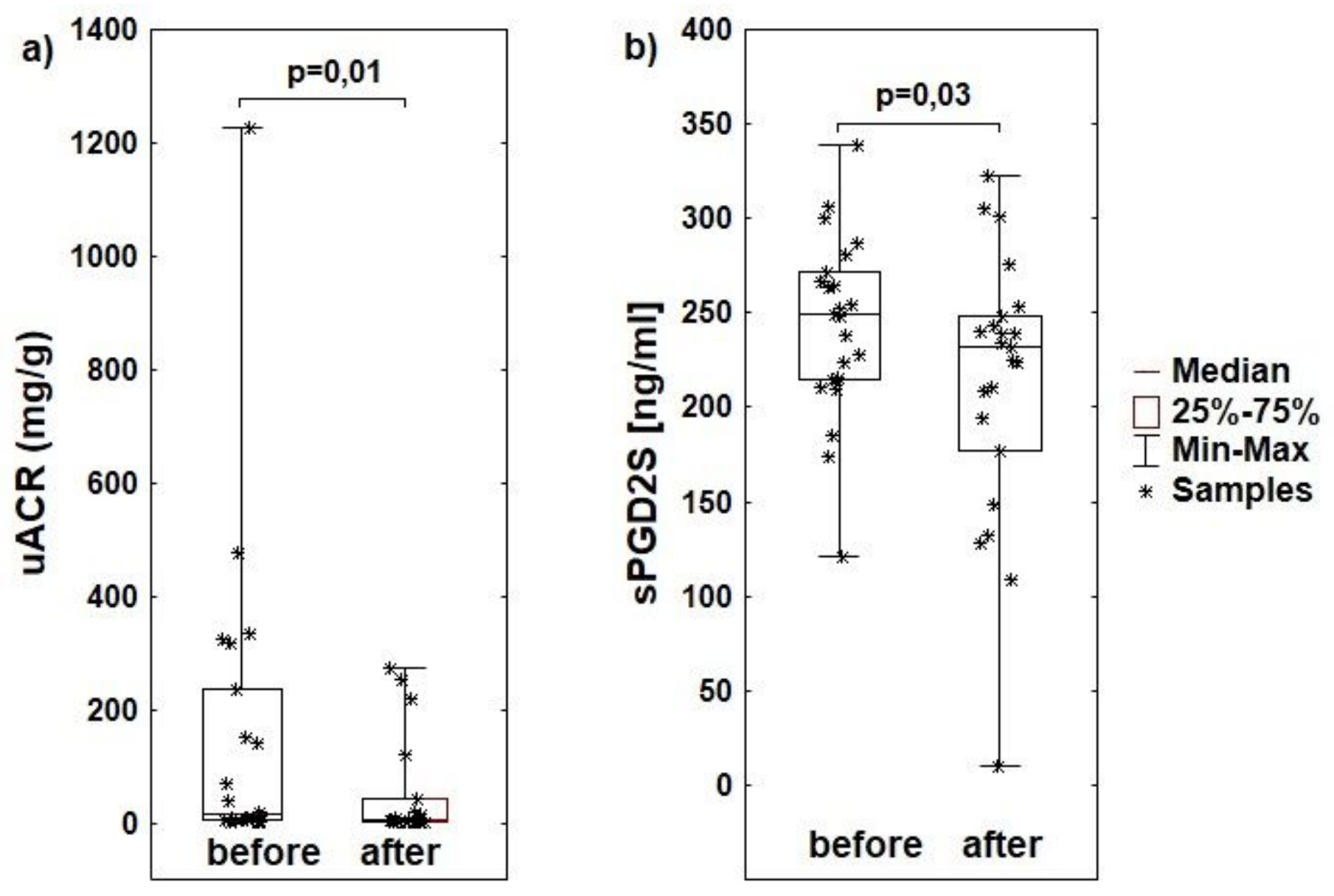

Response to CRT

Figure 2

Graph showing statistically significant changes in UACR (a) and SPGD2S (b) before and 3 months after CRT in the CRT responders group $(n=21)$. In addition, a statistically significant increase in UNGAL concentration and a significant decrease in uCysC concentration in CRT non-responders group 3 months after CRT was observed. The responders did not show any statistically significant changes in either urine biomarkers. The significant relationships observed in the CRT non - responders group are shown in Figure 3. 

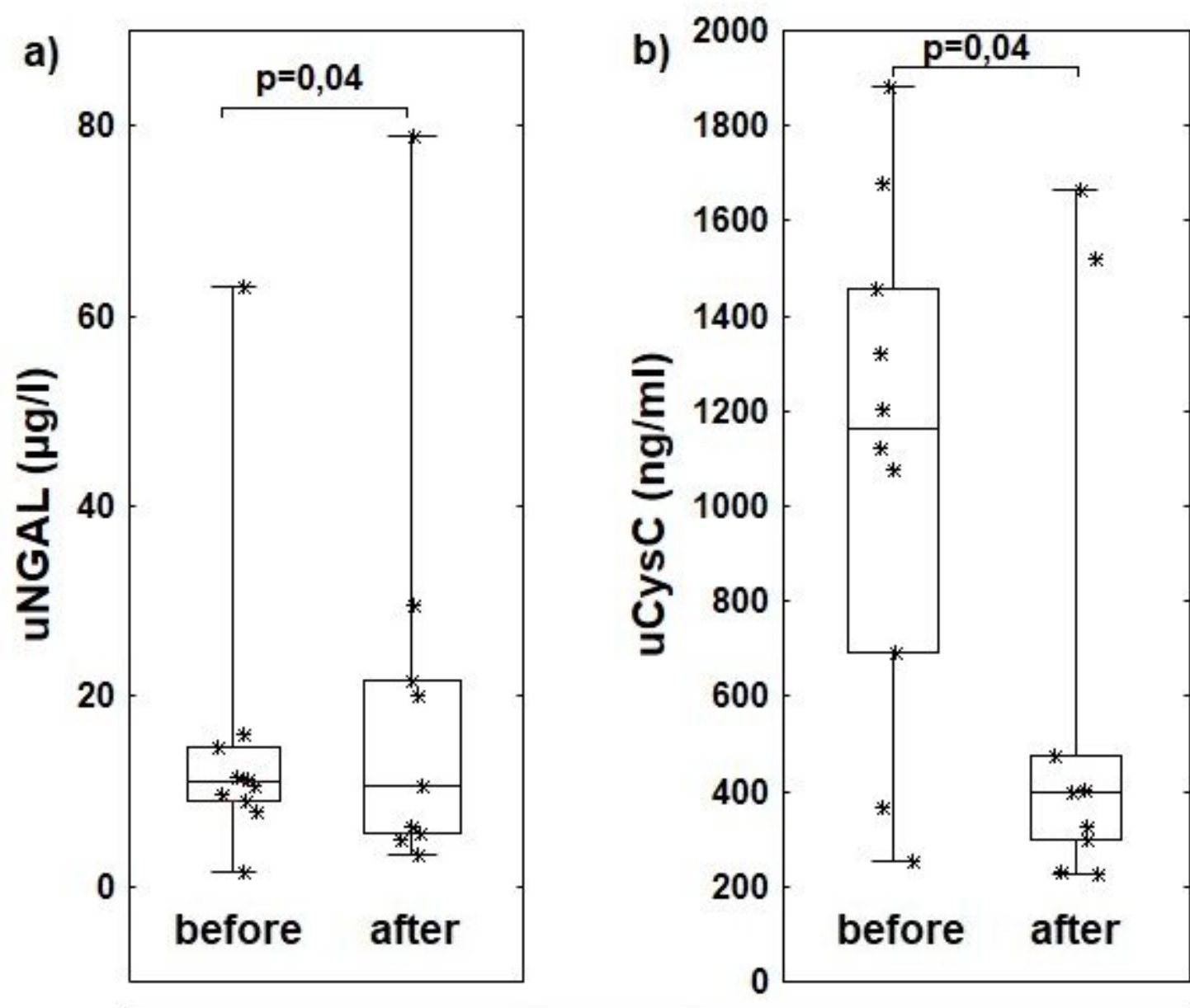

- Median $25 \%-75 \%$

I Min-Max

* Samples

\section{Non-response to CRT}

Figure 3

Graph showing statistically significant changes in UNGAL (a) and uCysC (b) before and 3 months after CRT in the CRT non - responders group $(n=12)$. At the same time, in both responders and nonresponders, no statistically significant changes in other biomarkers were observed. 